Myriam Gerhard

Hegel und die logische Frage 


\section{Hegel-Jahrbuch Sonderband}

Herausgegeben von

Andreas Arndt, Myriam Gerhard und Jure Zovko

\section{Band 6}


Myriam Gerhard

Hegel und die

logische Frage

DE GRUYTER 
ISBN 978-3-11-044034-8

e-ISBN (PDF) 978-3-11-043221-3

e-ISBN (EPUB) 978-3-11-043234-3

ISSN 2199-8167

Library of Congress Cataloging-in-Publication Data

A CIP catalog record for this book has been applied for at the Library of Congress.

Bibliografische Information der Deutschen Nationalbibliothek

Die Deutsche Nationalbibliothek verzeichnet diese Publikation in der Deutschen Nationalbibliografie; detaillierte bibliografische Daten sind im Internet über http://dnb.dnb.de abrufbar.

(C) 2015 Walter de Gruyter GmbH, Berlin/Boston

Satz: Konrad Triltsch, Print und digitale Medien GmbH, Ochsenfurt

Druck und Bindung: Hubert \& Co GmbH \& Co. KG, Göttingen

@ Gedruckt auf säurefreiem Papier

Printed in Germany

www.degruyter.com 